\title{
Culture-based analysis of 'Cave Silver' biofilms on Rocks in the former Homestake mine in South Dakota, USA
}

\author{
Amanpreet K. Brar ${ }^{1}$ and David Bergmann ${ }^{2 *}$ \\ 'Florida State University, 319 Stadium Dr., Tallahassee, FL 32306-4295, USA \\ ${ }^{2}$ Black Hills State University, 1200 W. University St., Spearfish, SD 57789, USA
}

\begin{abstract}
Tunnels in a warm, humid area of the $1478 \mathrm{~m}$ level of the Sanford Underground Research Facility (SURF), located in a former gold mine in South Dakota, USA, host irregular, thin whitish, iridescent biofilms, which appear superficially similar to 'cave silver' biofilms described from limestone and lava tube caves, despite the higher rock temperature $\left(32^{\circ} \mathrm{C}\right)$ and differing rock surface (phyllite) present at SURF. In this study, we investigated the diversity of cultivable bacteria constituting the cave silver by using several media: $\mathrm{CN}$ agar, CN gellan gum and $0.1 \mathrm{X}$ R2A agar. The highest colony count (CFU/g of sample) was observed on $0.1 \mathrm{X}$ R2A medium. The bacterial strains were grouped into 39 distinct genotypes by randomly amplified polymorphic DNA (RAPD) analysis. In addition, the bacterial strains were further characterized based on their phenotypic and biochemical properties. 16S rRNA gene sequencing classified the cave silver isolates into three major bacterial phyla: Proteobacteria, Actinobacteria and Firmicutes. Isolates included some known genera; such as Taonella, Dongia, Mesorhizobium, Ralstonia, Pedomicrobium, Bauldia, Pseudolabrys, Reyrnella, Mizugakiibacter, Bradyrhizobium, Pseudomonas, Micrococcus, Sporichthya, Allokutzneria, Amycolatopsis, Pseudonocardia, and Paenibacillus. Several isolates; related to Taonella, Dongia and Variibacter, may represent undescribed genera.
\end{abstract}

Keywords: $\quad$ bacteria, biofilms, underground, cultivable, 16S rRNA genes

Received 31 August 2018; Revised 8 March 2019; Accepted 15 May 2019

Citation: Brar A.K. and Bergmann D., 2019. Culture-based analysis of 'Cave Silver' biofilms on Rocks in the former Homestake mine in South Dakota, USA. International Journal of Speleology, 48 (2), 145-154. Tampa, FL (USA) ISSN 0392-6672 https://doi.org/10.5038/1827-806X.48.2.2226

\section{INTRODUCTION}

Deep underground ecosystems, such as caves and mines, lack light, have low amounts of organic matter, and may have reduced inorganic molecules which can support chemolithotrophy (Barton \& Jurado 2007, Tebo et al., 2015). Microbial-induced mineralization processes have been described in various cave ecosystems (Northup et al., 2003; Engel et al., 2004; Curry et al., 2009). Some caves, including limestone caves (Portillo et al., 2008; Pašic et al., 2010; Mulec et al., 2015), lava-tube caves (Northrup et al., 2011) and quartzite caves (Sauro et al., 2018), contain extensive, flat, microbial biofilms, which may be whitish, golden, or tan in color, which are dominated by members of the bacterial phyla Acidobacteria, Actinobacteria, Chloroflexi, and Nitrospirae. In some cases, these biofilms condense minute droplets of water and have an iridescent appearance and have been referred to as "cave silver" (Pašic et al., 2010). The biofilms in lavatube caves have drawn the attention of astrobiologists, who hypothesize that microbes may exist on similar caves on the planet Mars (Northup et al., 2011). Recently, biofilms similar in appearance to "cave silver" biofilms have been discovered in a segment of the former Homestake mine in South Dakota at a depth of $1478 \mathrm{~m}$ below the surface.

The Homestake mine was one of the largest $(592 \mathrm{~km}$ of tunnels) and deepest $(2.4 \mathrm{~km})$ gold mines in North America until it was closed in 2003 (Murdoch et al., 2012). In 2007, portions of the former mine were reopened as the Sanford Underground Research Facility (SURF), providing an opportunity to the biologists, astrophysicists, geoscientists and engineers to explore the subsurface environment (Lesko, 2011).

SURF consists of different levels, each with its own microbial ecosystems, depending on the geochemistry of rocks, rock fracture water, and sediment, as well as the temperature, $\mathrm{pH}$, humidity and composition of gasses in tunnels (Osburn, 2014). 16S rRNA gene analysis of fracture and drainage water, sediments, and biofilms sustained by fracture water flowing over rocks indicate a high diversity of chemoautotrophic bacteria such as sulfide-oxidizers, ammonia- 
oxidizers, iron-oxidizers, methane-oxidizers, and sulfate-reducers, as well as chemoheterotrophs (Rastogi et al., 2009b; Waddell et al., 2010). Little culture-based work has been done on SURF microbial communities, apart from the isolation of a few groups of microbes of industrial interest, such as cyanidedegrading Pseudomonas (Mudder \& Whitlock, 1984); thermophilic and mesophilic cellulose-degrading bacteria of the genera Bacillus, Brevibacillus, and Paenibacillus (Rastogi et al., 2009a); and several species of Clostrium capable of fermentation of glucose, xylose, and glycerol (Rastogi et al., 2013).

On the $1478 \mathrm{~m}$ deep level of SURF, at a site known as the 17 Ledge, warm $\left(32^{\circ} \mathrm{C}\right)$ air, saturated with water vapor, meets cooler $\left(25^{\circ} \mathrm{C}\right)$ air, causing condensation on the walls of the tunnel. The rocks in this region consist of phyllites of the Poorman formation. These phyllites consist mainly of sericite, biotite, graphite, ankerite, and quartz, with pyrrhotite also present (Caddey, 1991). In a zone from 8 to $60 \mathrm{~m}$ beyond a flowing diamond drill hole known as "Thiothrix Falls", the site of an astrobiology experiment, areas of thin (less than $1 \mathrm{~mm}$ thick) iridescent biofilms frequently occur on the walls and ceilings of the tunnel. These nacreous white biofilms appear silvery due to the light scattered by the water droplets covering their surface. These biofilms were not characterized by previously published work on SURF microbiology cited above. These biofilms appeared similar in appearance to biofilms known as "Cave Silver" found in limestone caves in Europe and lava-tube caves. Data from high-throughput bacterial 16S rRNA gene sequencing indicated that the cave silver biofilms consisted primarily of phyla Proteobacteria and Actinobacteria, Acidobacteria, and Chloroflexi, with Bacteriodetes, Cynobacteria, Firmicutes, Chlorobi, Gemmatimonadetes, Nitrospirae, Plantomycetes, and Verrucomicrobia also present (Thompson \& Bergmann, 2016). The presence of Actinobacteria is of interest because this phylum of bacteria is the source of the majority of antibacterial drugs (SuellSilva, 2013). Hence, it is desirable to isolate bacteria from SURF cave silver, both to characterize novel taxa of bacteria and to culture Actinobacteria which might be tested for antimicrobial agents.

Although there are similarities in the appearance of the SURF cave silver biofilms with those of limestone and lava tube caves, the geology of the phyllite rock faces in SURF is very different from the limestone or solidified lava surfaces in caves. Also, the depth of the cave silver site in SURF is much greater than the limestone or lava-tube caves (near the surface vs. $1478 \mathrm{~m})$, and the temperature is considerably higher $\left(10^{\circ}-19^{\circ} \mathrm{C}\right.$ vs. $\left.28-30^{\circ} \mathrm{C}\right)$. Hence, the environmental forces influencing the SURF biofilms are unique. With the exception of two studies by Mulec et al. (2015) and Velikonja et al. (2014) in limestone caves, there have been few recent culture based studies on cave silver biofilms, despite the prevalence of possible antibiotic-producing Actinobacteria in these biofilms. The aim of this project was to isolate and culture bacteria from SURF cave silver biofilms by using two different media: more nutrient rich, $\mathrm{CN}$ medium
(0.1\% Casamino acids, $0.1 \%$ Nutrient broth with agar or GELRITE) and a more nutrient deficient medium, diluted R2A (0.1X R2A agar, Reasoner \& Geldreich, 1985). We characterized phenotypic characteristics of these isolates and identified them by sequencing $16 \mathrm{~S}$ rRNA genes. We then compared the taxa recovered by culture-based techniques with those known to be present in the biofilms based on culture-independent techniques.

\section{MATERIALS AND METHODS}

\section{Sample collection}

Cave silver biofilm samples were obtained in October 2015, at a depth of $1478 \mathrm{~m}$ at the 17 Ledge area of SURF, about 10-30 m beyond "Thiothrix Falls". The microbial communities were primarily over $1.5 \mathrm{~m}$ high on the walls and ceilings of the tunnel, forming irregular, thin, silvery patches, each $25-400 \mathrm{~cm}^{2}$ in area. Four samples were taken by gently scraping off the biofilms with a sterile scalpel into 15-ml Falcon tubes. After collection, the samples were transported to the lab at an ambient temperature and were then stored at $4^{\circ} \mathrm{C}$ until sample preparation (within 16 hours). Each sample weighed approximately $0.05 \mathrm{~g}$ and was homogenized in $9 \mathrm{~mL}$ Phosphate Buffered Saline $(10 \mathrm{mM}$ potassium phosphate, $0.8 \% \mathrm{NaCl}, \mathrm{pH}$ $7.5)$ and further serially diluted to $10^{-5}$ before being immediately spread-plated onto solid media.

\section{Inoculation of media}

$\mathrm{CN}$ agar, CN gellan gum, and 0.1X R2A agar media were selected to recover viable bacteria from the biofilm samples. For CN based medium, Casamino acids and Nutrient broth were added at a concentration of $1 \mathrm{~g}$ each per liter of distilled water and solidified with 1.5 agar or $1.2 \%$ gellan gum (Phytagel, Sigma-Aldrich),(Harris, 1985). A low nutrient, 0.1X R2A medium was used to recover slow-growing, oligotrophic microbes from the cave silver biofilm. 0.1X SURF R2A agar medium contained $0.1 \%$ R2A broth, $0.5 \%$ trace ATCC elements, 0.5\% ATCC vitamin solution (American Type Culture Collection), $5 \%(\mathrm{~W} / \mathrm{V})$ cold filtered aqueous SURF sediment extract (dry sediment from tunnels where the cave silver biofilms were growing), and 1.5\% agar. Cycloheximide $(100 \mathrm{mg} / \mathrm{mL}$ final concentration) and nystatin $(50 \mathrm{mg} / \mathrm{mL}$ final concentration) (SigmaAldrich) were added to the media to prevent fungal infection. $100 \mu \mathrm{L}$ aliquots of diluted microbial suspension from each dilution were transferred to Petri plates (triplicate of each dilution) containing the sterile growth media and spread over the surface with a sterile glass spreading rod (Silva et al., 2013). The inoculated Petri plates were incubated at $28^{\circ} \mathrm{C}$ for $2-3$ weeks and colonies counted to calculate the $\mathrm{CFU} / \mathrm{ml}$ of homogenized sample (Tomasiewicz et al., 1980; Van Der Linde et al., 1999).

A total of 164 bacterial colonies from $\mathrm{CN}$ agar, $\mathrm{CN}$ gellan gum, and 0.1X R2A agar media were selected randomly (colonies nearest to the center of a plate were selected) and were streaked onto Petri plates of $1 \mathrm{X} \mathrm{CN}$ agar media or 1 R2A gar media (respectively) with 100 $\mathrm{mg} / \mathrm{mL}$ cycloheximide and $50 \mathrm{mg} / \mathrm{mL}$ nystatin. Single 
colonies of each isolate were then transferred to either CN agar or1X R2A slants, respectively. Pure cultures in R2 broth were preserved in 20\% glycerol and frozen at $-80^{\circ} \mathrm{C}$ for future use (Yuan et al., 2014).

\section{Extraction of genomic DNA from isolates and Random Amplified Polymorphic DNA (RAPD) PCR}

Genomic DNA was extracted from 152 bacterial isolates using a DNeasy Blood and Tissue Kit (Qiagen Inc.), following the protocol for gram-positive bacteria. RAPD PCR was performed using the BOXAIR primer (5'-CTA CGG CAA GGC GAC GCT GAC G-3') (Versalovic et al., 1994). The PCR reaction mixture $(15 \mu \mathrm{L})$ for isolates contained $2 \mu \mathrm{L}$ of template DNA, 10x BSA (Nagai et al., 1998), 10 mM BOX-AR1 primer, deoxynucleoside triphosphates (each $10 \mathrm{mM}$ ), 10X HotMaster Taq buffer with magnesium (5 Prime Inc.) and $0.5 \mathrm{U}$ HotMaster Taq DNA polymerase. PCR was carried out under the following conditions: initial denaturation at $94^{\circ} \mathrm{C}$ for $2 \mathrm{~min} ; 30$ cycles of denaturation at $94^{\circ} \mathrm{C}$ for $20 \mathrm{~s}$, annealing at $53^{\circ} \mathrm{C}$ for $1 \mathrm{~min}$, and extension at $65^{\circ} \mathrm{C}$ for $4 \mathrm{~min}$, and a final extension at $65^{\circ} \mathrm{C}$ for $8 \mathrm{~min}$. For DNA fingerprinting of 0.1X R2A agar isolates, 5 Prime HotMasterMix (2.5X) was used for preparing the reaction mixture. The PCR products were separated by electrophoresis on a $2 \%$ agarose gel and stained with ethidium bromide as described by Suel-Silva et al. (2013). The degree of similarity of PCR amplicon sizes from the different isolates was evaluated by visual observation, and the isolates classified into operational taxonomic units (OTUs).

\section{Phenotypic Characterization of isolates and sequencing of $16 \mathrm{~S}$ rRNAgGenes}

Forty-six representatives, at least one for of each RAPD OTU group, were selected for phenotypic characterization. These isolates were characterized by observing colony morphology, as well as cell shape and arrangement following gram-staining, as described by Moyes et al. (2009). The ability of bacterial isolates to ferment and/or oxidize glucose was tested by using glucose phenol red broth and Hugh and Leifson's O-F medium (McFaddin, 1980). The presence of cytochrome oxidase and catalase was tested as described by McFaddin (1980). Isolates were grown in nitrate broth to test for the nitrate reductase (McFaddin, 1980).

Representative isolates from each RAPD OTU were also used for PCR amplification and sequencing of $16 \mathrm{~S}$ rRNA gene. The $16 \mathrm{~S}$ rRNA gene was amplified with oligonucleotide primers $27 \mathrm{~F}$ (5'-GAGTTTGATCMTGGCTCAG-3') and 1492R (5'GGT TAC CTT GTT ACG ACT T-3' (Weisburg et al., 1991). The reaction mixture $(15 \mu \mathrm{L})$ contained 5 Prime HotMasterMix (2.5x), 10x BSA, 27F and 1492R primers $(10 \mu \mathrm{M})$ and $2 \mu \mathrm{L}$ genomic DNA. The PCR reaction started with pre-denaturation at $94^{\circ} \mathrm{C}$ for 2 min, followed by 32 cycles of denaturation at $94^{\circ} \mathrm{C}$ for $30 \mathrm{sec}$, annealing at $57^{\circ} \mathrm{C}$ for $15 \mathrm{sec}$ and $4 \mathrm{~min}$ of extension at $65^{\circ} \mathrm{C}$ with a final extension at $65^{\circ} \mathrm{C}$ for 7 min. After cleaning the amplified product with ExoSAP-
IT (Affymetrix, USA) sequencing was performed with primers 27F (AGAGTTTGATCMTGGCTCAG), $338 \mathrm{~F}$ (ACTCCTACGGGAGGCAGCAG) and 1390R (CGGTGTGTACAAGGCCC) (De Lillo et al., 2006; Huse et al., 2008; Fortuna et al., 2011) using BigDye Terminator v1.1 Cycle Sequencing Kit in ABI 3130xl Genetic Analyzer Applied Biosystems, USA) at Black Hills State University (BHSU) Westcore .

The 16SrRNA gene sequences were checked for the presence of chimeras using the Bellerophon server (http://foo.maths.uq.edu.au/ huber/bellerophon.pl) and the closest matches among cultured isolates were found using the BLASTN program on the NCBI database (https://blast.ncbi.nlm.nih.gov/Blast.cgi? PROGRAM=blastn\&PAGE $\_$TYPE=BlastSearch\&LINK

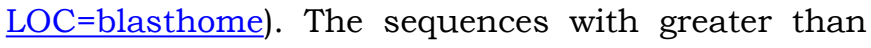
$97 \%$ identity to the top BLAST hit were considered resolved at species level and $95-97 \%$ at genus level (Rhoads et al. 2012). The $16 \mathrm{~S}$ rRNA gene sequences were also classified using the Classifier program (Wang et al. 2007) at the Ribosomal Database Project website (https://rdp.cme.msu.edu/classifier/classifier.jsp). After aligning the sequences using MUSCLE (Edgar, 2004), a phylogenetic tree was constructed using the Jukes and Cantor (1969) model for the neighborjoining method in the CLC Bio software, Version 11 (Qiagen, Inc.). 16S rRNA gene sequences from isolates were deposited in the GenBank database under accession numbers MH669510-MH669553.

\section{RESULTS}

For this study, two types of high-nutrient $\mathrm{CN}$ based media were compared; $\mathrm{CN}$ agar and $\mathrm{CN}$ gellan gum, both of which contain Casamino acids and beef extract but differed in the type of solidifying agent used. This was done to determine the effect of gelling agent (agar or gellan gum) for culturing of cave silver biofilms. We also tested a low nutrient medium, 0.1X R2A, an agar-based medium. Numbers of colony forming units per $\mathrm{g}$ of homogenized biofilm (CFU/g) were for slightly higher for the same samples for $\mathrm{CN}$ gellan gum than for $\mathrm{CN}$ agar media, but the highest counts were obtained for a sample plated on low nutrient 0.1X R2A medium (Fig. 1).

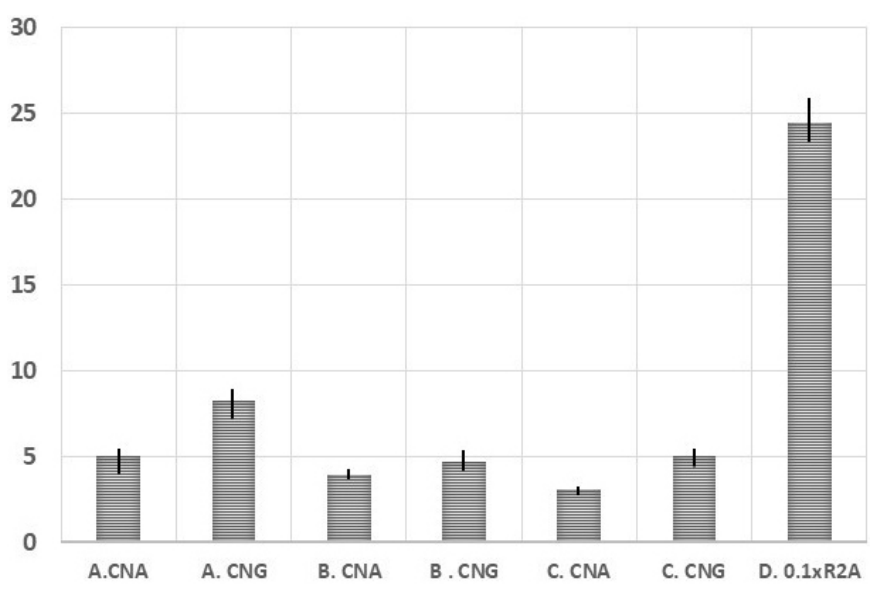

Fig. 1. Colony forming units (CFU) per gram of SURF cave silver samples. Samples A, B, and C were plated on $\mathrm{CN}$ agar and $\mathrm{CN}$ gellan gum, while sample D was plated on $0.1 \times$ R2A. Standard errors of the mean are indicated by the vertical bars. 
A total of 164 bacterial isolates were obtained; 118 from CN agar/CN gellan gum and 46 from 0.1X R2A agar media. Some $\mathrm{CN}$ and $0.1 \mathrm{X}$ R2A based isolates were lost during the sub-culturing process due to fungal contamination, while seven isolates could not be separated as pure cultures.

Of the 118 bacterial isolates recovered from $\mathrm{CN}$ based media, 46.6\% had white, circular, raised and mucoid colonies of mostly gram-negative cocci; $17.7 \%$ formed white, powdery, wrinkled colonies with welldeveloped aerial mycelia; $8.4 \%$ formed some round, pink colored colonies of gram-negative coccobacilli; $5.1 \%$ formed smooth, yellow colored colonies (which were later confirmed by $16 \mathrm{~S}$ rRNA analysis to be Actinobacteria); and the remaining $22.0 \%$ of isolates included white or transparent colonies.
Of the $460.1 \mathrm{X}$ R2A isolates, $32.6 \%$ consisted of white, convex colonies forming an aerial mycelium. These colonies produced a pink colored diffusible pigment, turning the media completely black after 4-5 days of incubation. The 16S rRNA analysis revealed that they were Actinobacteria belonging to the genus Amycolatopsis. The second most common (19.6\%) group included whitish, mucoid colonies which were later found to be Bradyrhizobium.

Random Amplified Polymorphic DNA (RAPD) was used to classify isolates into OTUs. Isolates from $1 \mathrm{X}$ CN media and 0.1X R2A media were classified into 25 and 14 RAPD groups, respectively (Fig. 2, Table 1). Largely dissimilar RAPD groups were observed for isolates from the $1 \mathrm{X} \mathrm{CN}$ agar/ gellan gum and the 0.1X R2A agar media.

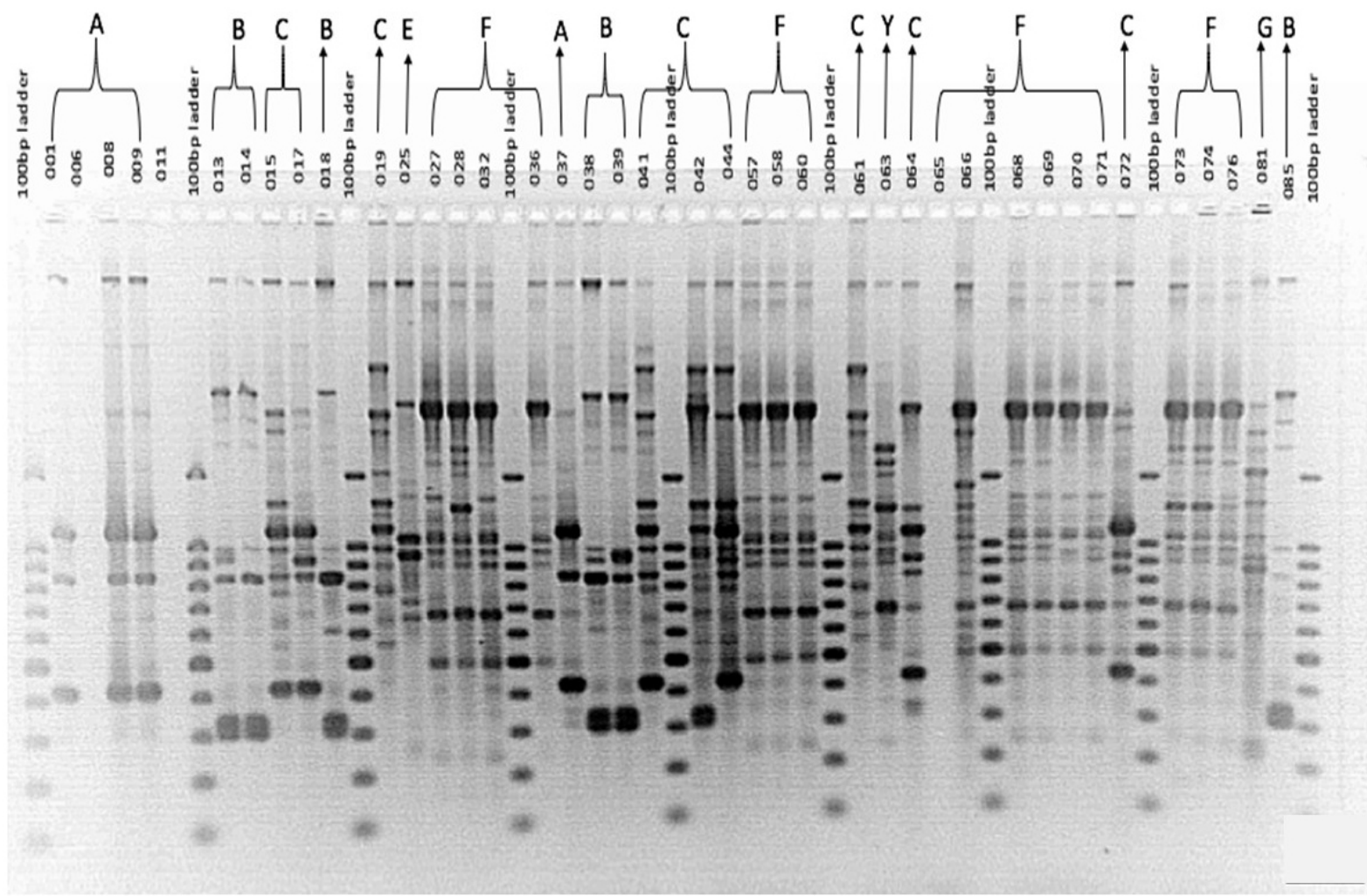

Fig. 2. 2.0\% agarose gel showing an example of RAPD amplicons from 37 SURF cave silver isolates from CN media. On the basis of amplicon sizes, the isolates were assigned to RAPD genotype groups (A, B, C, etc.). The100 BP ladder has ten DNA fragments, differing in size by $100 \mathrm{BP}$, from 100 to $1000 \mathrm{BP}$, and also a fragment $1500 \mathrm{BP}$.

Table 1. Genotypic characteristics of isolates from SURF cave silver biofilms. Isolates ending in "C" are from CN media, while those ending in "R" are from 0.1X R2A media. Letters designate RAPD groups with a common pattern of amplicons. The closest match to the sequence of the 16S rRNA gene in the cultured isolates in the NCBI database is listed, along with the percent identity of the match. Isolates from CN (a) and R2A media (b).

(a)

\begin{tabular}{|c|c|c|c|c|c|}
\hline Isolate & $\begin{array}{c}\text { RAPD } \\
\text { OTU }\end{array}$ & 16S rDNA closest match & Family & $\begin{array}{c}\text { Percent } \\
\text { Identity }\end{array}$ & Habitat \\
\hline HS001C & A & Taonella mepensis H1 & Rhodospirillaceae & $90 \%$ & activated sludge \\
\hline HS009C & A & Taonella mepensis H1 & Rhodospirillaceae & $91 \%$ & activated sludge \\
\hline HS014C & B & Taonella mepensis H1 & Rhodospirillaceae & $90 \%$ & activated sludge \\
\hline HS039C & B & Taonella mepensis H1 & Rhodospirillaceae & $91 \%$ & activated sludge \\
\hline HS017C & C & Taonella mepensis H1 & Rhodospirillaceae & $91 \%$ & activated sludge \\
\hline HS125C & H & Taonella mepensis H1 & Rhodospirillaceae & $91 \%$ & activated sludge \\
\hline HS062C & Q & Taonella mepensis H1 & Rhodospirillaceae & $99 \%$ & activated sludge \\
\hline HS150C & W & Taonella mepensis H1 & Rhodospirillaceae & $92 \%$ & activated sludge \\
\hline HS025C & E & Dongi rigui 04SU4-P & Rhodospirillaceae & $91 \%$ & freshwater wetland \\
\hline HS153C & V & Dongi rigui 04SU4-P & Rhodospirillaceae & $91 \%$ & freshwater wetland \\
\hline HS063C & Y & Dongi rigui 04SU4-P & Rhodospirillaceae & $91 \%$ & freshwater wetland \\
\hline HS101C & F & Dongia mobilis LM22 & Rhodospirillaceae & $95 \%$ & malachite green activated sludge \\
\hline
\end{tabular}




\begin{tabular}{|c|c|c|c|c|c|}
\hline HS130C & T & Dongia mobilis LM22 & Rhodospirillaceae & $95 \%$ & malachite green activated sludge \\
\hline HS112C & I & Bradyrhizobium japonicum DSM30131 & Bradyrhizobiacae & $99 \%$ & soybean root nodules \\
\hline HS022C & I & Bradyrhizobium japonicum DSM30131 & Bradyrhizobiacae & $99 \%$ & soybean root nodules \\
\hline HS081C & G & Mesorhizobium acaciae RITF471 & Phyllobacteriaceae & $99 \%$ & Acacia melanoxylon root nodules \\
\hline HS129C & J & Micrococcus aloverae AE-6 & Micrococcaceae & $99 \%$ & Aloe barbadensis leaves \\
\hline HS035C & J & Micrococus yunnanensis YM65004 & Micrococcaceae & $99 \%$ & endophytic, Catharanthus roseus \\
\hline HS092C & K & Ralstonia picketti NBRC102503 & Burkholderiaceae & $100 \%$ & soil, water, clinical samples \\
\hline HS067C & K & Ralstonia picketti NBRC102503 & Burkholderiaceae & $100 \%$ & soil, water, clinical samples \\
\hline HS067C & L & Allokutzneria albata R761-7 & Pseudonocardiaceae & $99 \%$ & soil \\
\hline HS117C & N & Pseudonocardia spinospora LM141 & Pseudonocardiaceae & $98 \%$ & gold mine sediment \\
\hline HS050C & M & Pseudonocardia eucalypti EUM374 & Pseudonocardiaceae & $96 \%$ & Eucalyptus microcarpa root \\
\hline HS107C & S & Paenibacillus favisporus GMP01 & Paenibacillaceae & $99 \%$ & cow feces \\
\hline HS103C & D & Sporichthya polymorpha DSM43042 & Sporichthyaceae & $100 \%$ & soil \\
\hline HS103C & X & Variibacter gotjawwalensis GI-W30 & Bradyrhizobiaceae & $94 \%$ & soil \\
\hline HS138C & U & Pedomicrobium manganicum ATCC & Hyphomicrobiaceae & $95 \%$ & soil, water \\
\hline
\end{tabular}

(b)

\begin{tabular}{|c|c|c|c|c|c|}
\hline Isolate & $\begin{array}{l}\text { RAPD } \\
\text { OTU }\end{array}$ & 16S rDNA closest match & Family & $\begin{array}{l}\text { Percent } \\
\text { Identity }\end{array}$ & Habitat \\
\hline HS013R & h' & Bradyrhizobium japonicum DSM 30131 & Bradyrhizobiaceae & $99 \%$ & soybean root nodules \\
\hline HS099R & h' & Bradyrhizobium japonicum DSM 30131 & Bradyrhizobiaceae & $99 \%$ & soybean root nodules \\
\hline $\mathrm{HS} 111 \mathrm{R}$ & h' & Bradyrhizobium japonicum DSM 30131 & Bradyrhizobiaceae & $99 \%$ & soybean root nodules \\
\hline HSO22R & $\mathrm{f}^{\prime}$ & Amycolatopsis helveola TT 00-43 & Pseudonocardiaceae & $95 \%$ & soil \\
\hline HS088R & $\mathrm{f}^{\prime}$ & Amycolatopsis helveola TT 00-43 & Pseudonocardiaceae & $95 \%$ & soil \\
\hline HS094R & $\mathrm{f}^{\prime}$ & Amycolatopsis helveola TT 00-43 & Pseudonocardiaceae & $95 \%$ & soil \\
\hline HS071R & $\mathrm{b}^{\prime}$ & Raeynella massillensis 521 & Rhodospirillaceae & $99 \%$ & freshwater \\
\hline HS058R & $\mathrm{e}^{\prime}$ & Dongia rigui 04SU4-P & Rhodospirillaceae & $92 \%$ & freshwater wetland \\
\hline HS083R & $\mathrm{k}^{\prime}$ & Pseudomonas aeruginosa DSM50071 & Psedomonadaceae & $99 \%$ & soil, water, clinical samples \\
\hline HS029R & I' & Pseudolabrys taiwanensis CC-BB4 & Xanthomonadaceae & $99 \%$ & soil \\
\hline HS067R & $\mathrm{c}^{\prime}$ & Pseudolabrys taiwanensis CC-BB4 & Xanthomonadaceae & $99 \%$ & soil \\
\hline HS096R & $\mathrm{c}^{\prime}$ & Pseudolabrys taiwanensis CC-BB4 & Xanthomonadaceae & $99 \%$ & soil \\
\hline HS070R & $1^{\prime}$ & Pseudolabrys taiwanensis CC-BB4 & Xanthomonadaceae & $99 \%$ & soil \\
\hline HSO03R & $d^{\prime}$ & $\begin{array}{c}\text { Pseudonocardia yunnanensis } \\
\text { YIM75926 }\end{array}$ & Pseudonocardiaceae & $98 \%$ & soil \\
\hline HS001R & $a^{\prime}$ & Pseudonocardia eucalypti EUM374 & Pseudonocardiaceae & $96 \%$ & Eucalyptus microcarpa root \\
\hline HS057R & g' & Paenibacillus lautus AB236D & Paenibacillaceae & $99 \%$ & clinical sample \\
\hline HS097R & $\mathrm{m}^{\prime}$ & Mizugakiibacter sediminis skMP5 & Xanthomonadaceae & $99 \%$ & thermophilic lake sediment \\
\hline HS068R & j' & Bauldia consociata 11 & $\begin{array}{l}\text { unclassified } \\
\text { Rhizobiales }\end{array}$ & $96 \%$ & soil, water \\
\hline HS063R & n' & Bauldia consociata 11 & $\begin{array}{l}\text { unclassified } \\
\text { Rhizobiales }\end{array}$ & $96 \%$ & soil, water \\
\hline
\end{tabular}

Forty-six isolates, one or more from each RAPD OTU group, were selected for phenotypic characterization. Most isolates had cells which were gram-negative coccobacilli or bacilli (later found to be Proteobacteria), or were gram-positive bacilli in chains or mycelia (later found to be Actinobacteria) (Supplementary Table 1). Most isolates were catalase and oxidase positive, with strictly respiratory metabolism (Supplementary Table 1).

The same 46 representatives of RAPD OTU groups were subjected to Sanger sequencing of nearly fulllength 16S rRNA gene to classify them according to bacterial taxa in the Ribosomal Database (Table 1). From the relative abundances of each RAPD OTU group among the isolates from $\mathrm{CN}$ and $\mathrm{R} 2 \mathrm{~A}$ media the relative abundance of these taxa among the isolates was estimated (Table 2 and Fig. 3). For all media combined (CN agar, CN GELRITE and 0.1X R2A agar), Proteobacteria was found to be the most abundant phylum (65.5\% of isolates) followed by Actinobacteria
(31.1\%) and Firmicutes (3.31\%). The CN based media were more successful in isolating Alphaproteobacteria, constituting $67 \%$ of 106 isolates. The low nutrient (0.1X R2A agar) media favored Actinobacteria and Alphaproteobacteria nearly equally, comprising 47\% and $42 \%$ of cultures respectively (Fig. 3). The low recovery of Firmicutes on both media is likely related to their low proportions $(2.6 \%)$ in the original biofilm, as determined by the culture independent study (Thompson \& Bergmann, 2016).

Based on sequence similarity of isolates to the sequences in GenBank, $80.1 \%$ and $43.7 \%$ were identified at genus (95\% identity or greater) and species $97 \%$ identity or greater) level. Nearly $20 \%$ of the 16S rRNA gene sequences from $\mathrm{CN}$ and $0.1 \mathrm{XR} 2 \mathrm{~A}$ derived isolates may represent novel genera; with closest similarities (less than 95\% identity) to Taonella, Dongia, and Variibacter (Fig. 4) (Schlaberg et al., 2012). A total of 17 different genera, 11 from 
Table 2. The abundance of each bacterial genus (number of isolates / percentage of isolates) from two kinds of media; CN agar/ gellan gum and $0.1 \mathrm{X}$ R2A agar.

\begin{tabular}{|c|c|c|}
\hline Bacterial Groups & $\begin{array}{c}\text { CN agar/GELRITE } \\
\text { (number of isolates/sequence similarity) }\end{array}$ & $\begin{array}{c}\text { 0.1X R2A agar } \\
\text { (number of isolates/sequence similarity) }\end{array}$ \\
\hline Alphaproteobacteria & $\begin{array}{c}\text { Dongia }(27 / 95 \%) \\
\text { Brayrhizobium }(10 / 99 \%) \\
\text { Taonella }(1 / 99 \%) \\
\text { Variibacter }(3 / 94 \%) \\
\text { Pedomicrobium }(2 / 95 \%) \\
\text { Mesorhizobium }(2 / 99 \%) \\
\text { Related to Taonella }(24 / 90-91 \%) \\
\text { Related to Dongia }(3 / 91 \%) \\
\end{array}$ & $\begin{array}{c}\text { Bradirhizobium (9/ 99\%) } \\
\text { Reynella (1/ 99\%) } \\
\text { Pseudolabrys (6/ 99\%) } \\
\text { Bauldia (2/ 96\%) } \\
\text { Related to Dongia (1/ 92\%) }\end{array}$ \\
\hline Betaproteobacteria & Ralstonia (5/ 100\%) & - \\
\hline Gammaproteobacteria & - & $\begin{array}{l}\text { Mizugakiibacter (3/ 99\%) } \\
\text { Pseudomonas (1/ 99\%) }\end{array}$ \\
\hline Actinobacteria & $\begin{array}{c}\text { Pseudonocardia (9/ 96-98\%) } \\
\text { Micrococcus (6/ 99\%) } \\
\text { Sporichthya (1/ 100\%) } \\
\text { Allokutnzeria (10/ 99\%) }\end{array}$ & $\begin{array}{l}\text { Pseudonocardia (6/ 96\%) } \\
\text { Amycolatopsis (15/ 95\%) }\end{array}$ \\
\hline Bacilli & Paenibacillus (4/ 99\%) & Paenibacillus (4/ 99\%) \\
\hline
\end{tabular}

Proteobacteria, five from Actinobacteria and one from Firmicutes were identified, including

Pseudolabrys, Reyranella, Mizugakiibacter, Bradyrhizobium, Pseudomonas, Micrococcus, Sporichthya, Allokutzneria, Amycolatopsis, Pseudonocardia, and Paenibacillus (Table 2 and Fig. 4). CN and R2A based media supported mainly different groups of microbial taxa, except the members of genera Bradyrhizobium, Pseudonocardia, and an unclassified group related to genera Dongia, which were present in both CN and R2A based media (Table 2). The 16S rRNA gene sequence of these isolates from $\mathrm{CN}$ and R2A based media align with $100 \%$ sequence identity. Nearly $81 \%$ of $\mathrm{CN}$ and $73 \%$ of R2A derived bacterial strains belongs to different taxonomic groups.

\section{DISCUSSION}

The two media tested in this study, high-nutrient $\mathrm{CN}$ agar and low nutrient $0.1 \mathrm{X}$ R2A, were both dominated by isolates from the Alphaproteobacteria and the Actinobacteria. However, the abundance of most genera of bacteria was very different from the two media. Hence, to isolate the most diverse assemblage of bacteria from an environmental sample, several media should be used (Velikonja et al., 2014).

The abundance of bacterial genera isolated from cave silver in SURF differed considerably from those isolated from cave silver in European caves. While Alphaproteobacteria such as Bradyrhizobium anduncharacterized Rhodospirillaceae, as well as Actinobacteria such as Pseudonocardia and Amycolatopsis were abundant in cave silver from SURF, Actinobacteria such as Streptomyces, Micrococcus, Rhodococcus, and Agrobacterium were most abundant in isolates from cave silver from Slovenia (Velikonja et al., 2014). A study by Mulec et al. (2014) used both high- and low-nutrient media to isolate microbes from yellowish biofilms in limestone caves in Slovenia recovered primarily Pseudomonas and Flavobacterium, as well as Streptomyces, Paenibacillus, Bacillus, and Staphylococcus.

Some of the major groups of bacteria noted by Thompson and Bergmann (2016) in cave silver in SURF using high-throughput sequencing of 16S rRNA gene; such as Pseudonocardia and other Pseudonocardiales, and Alphaproteobacteria, including Bradyrhizobium, Bauldia, and uncultured Rhodospirillaceae; were also represented among isolates from SURF cave

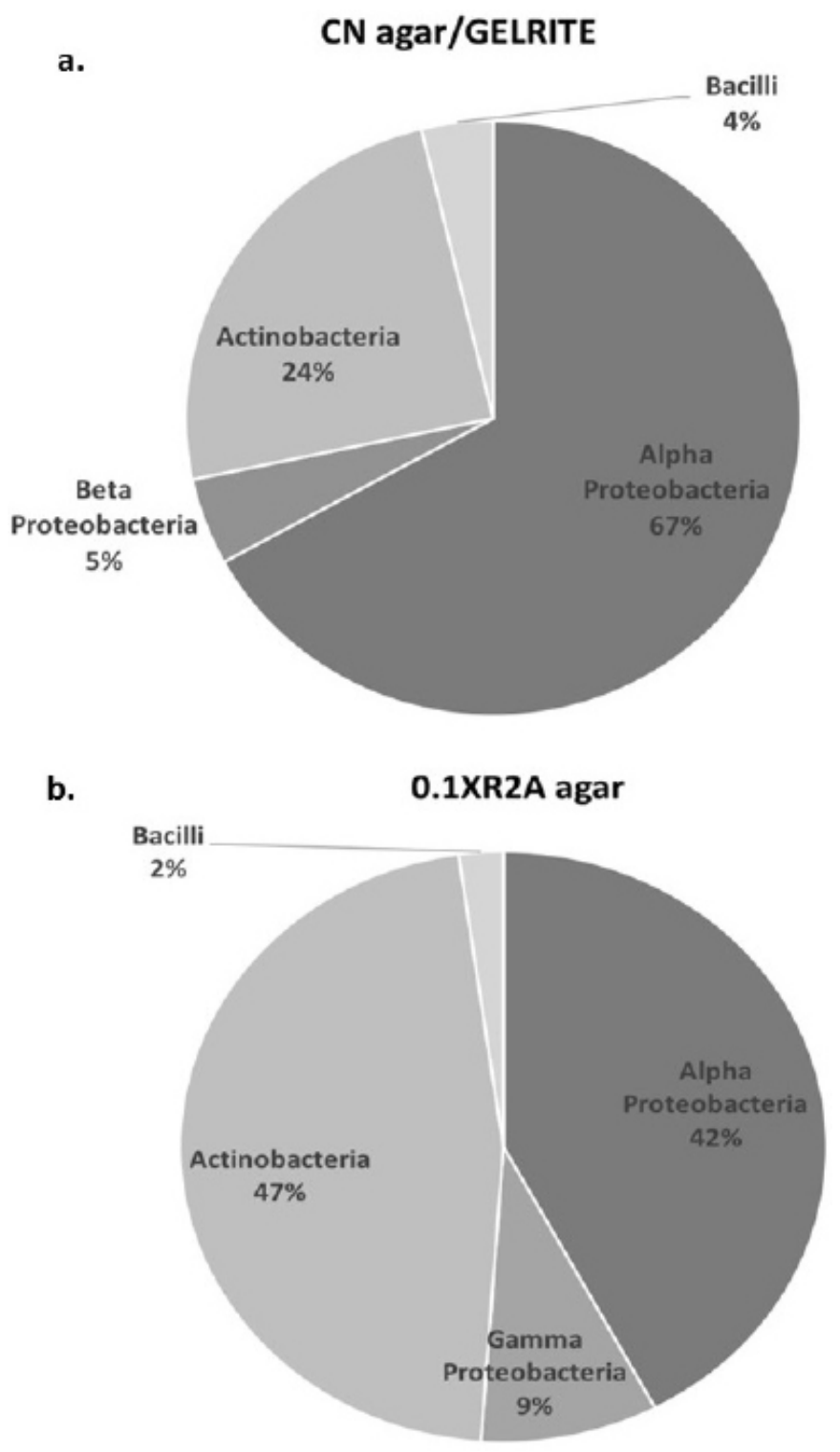

Fig. 3. Proportion of isolates in different bacterial classes on CN (a) and 0.1X R2A (b) media. 
a

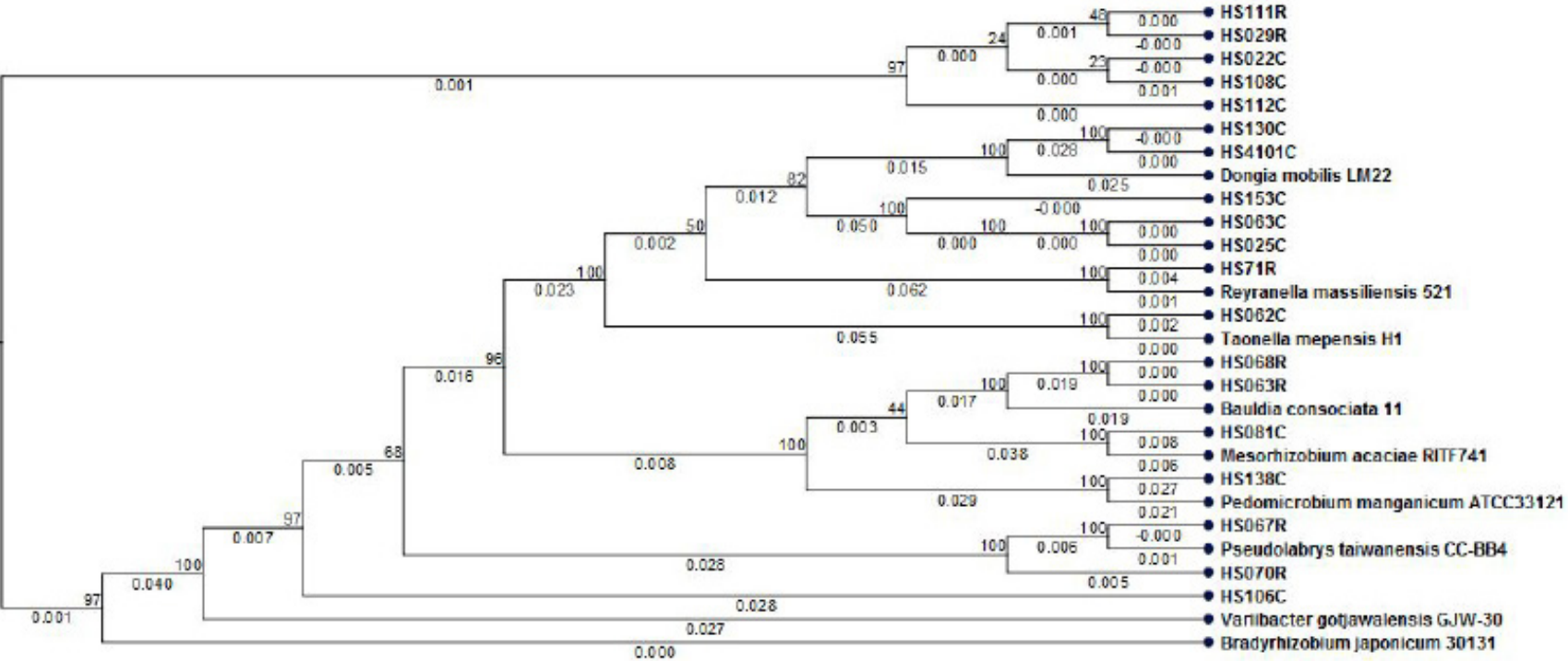

$\mathrm{b}$
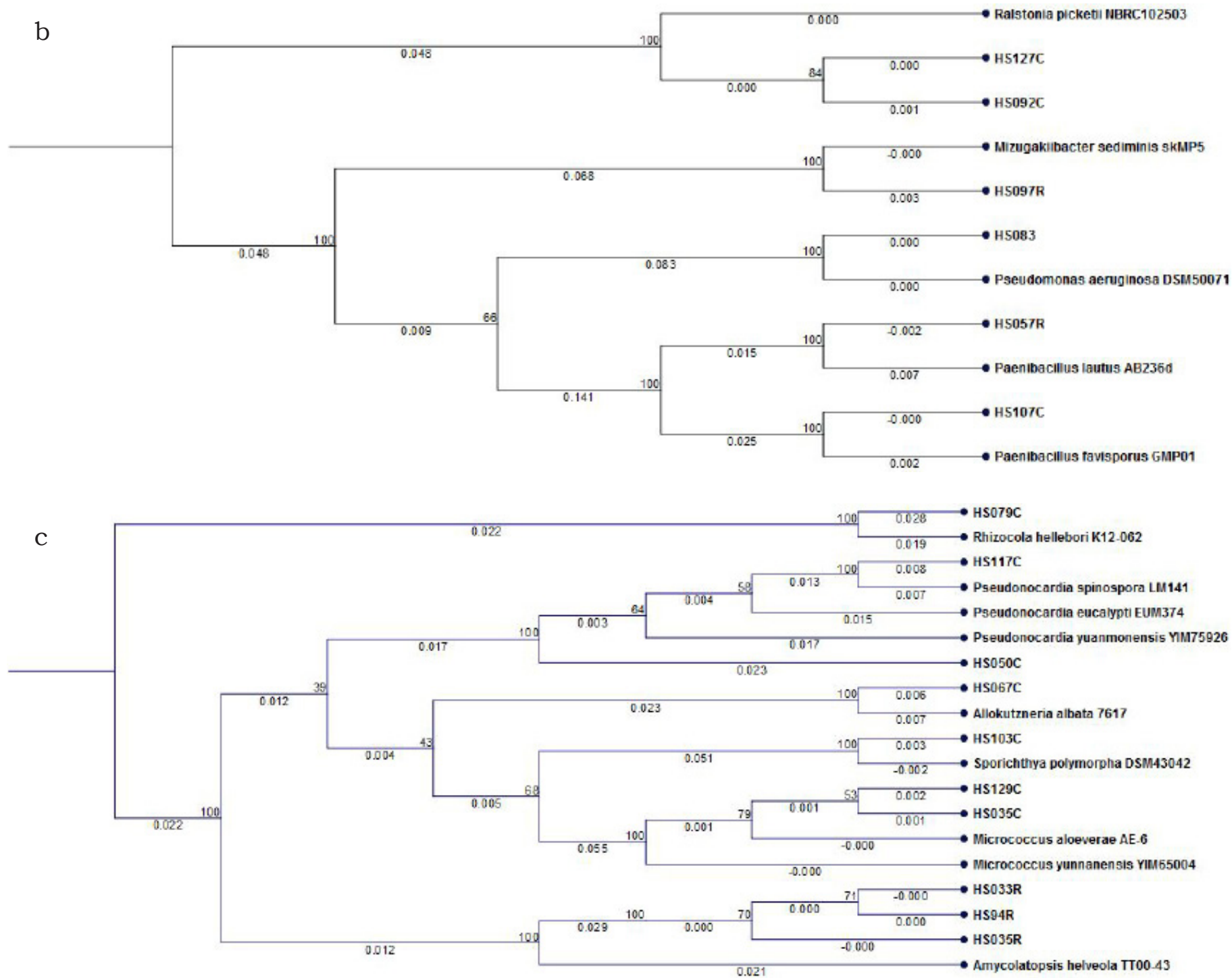

Fig. 4. Neighbor-joining trees illustrating the genetic relatedness of $16 \mathrm{~S}$ rRNA gene sequences from SURF cave silver isolates and their closed BLAST hits from cultured bacterial isolates in the NCBI database. Separate trees are shown for (a) Alphaproteobacteria, (b) Gammaproteobacteria and Firmicutes, and (c) Actinobacteria. The numbers at nodes denote percentages of 100 bootstrap samplings, and distances between branches are shown.

silver in this study. However, some phyla abundantly represented in SURF cave silver $16 \mathrm{~S}$ rRNA gene sequences; such as Acidobacteria, Chloroflexi, Nitrospirae, and Plactomycetes; were not isolated in this study. These latter four phyla were also abundant in $16 \mathrm{~S}$ rRNA gene libraries made from cave silver from
Slovenian limestone caves as well (Pasic et al., 2010) but none were isolated by Velikonja et al. (2014).

Four genera of Actinobacteria; Pseuodonocardia, Amycolatopsis, Allokutzneria, and Micrococcus; were abundant among isolates form SURF cave silver. Amycolatopsis and Allokutzneria species are 
chemoheterotrophs which can oxidize a variety of organic molecules, including sugars. The former genus is the source of numerous antibiotics, including vancomycin and rifamycin, while the latter is the source of anti-viral cycloviracins (Tomita et al., 1993; Tamura et al., 2010; Labeda \& Goodfellow, 2012).

Pseudonocardia includes species with diverse metabolism, mostly chemoheterotrophs which can utilize many sources of organic molecules, including hydrocarbons, some chemoautrophs, and one which can use carbon monoxide as its sole carbon source. (Labeda \& Goodfellow, 2012). Some species, which have mutalistic associations with ants, produce antimicrobial quinones (Carr et al., 2012).

The abundance of Bradyrhizobium among SURF cave silver isolates is interesting. Although often Bradyrhizobium species are often known for their ability to fix nitrogen and form mutualistic associations with legumes, other species of Bradyrhizobium are freeliving in the soil, and lack nitrogenase (VanInsberghe et al., 2015). Hence, it is uncertain if nitrogen fixation occurs in SURF cave silver.

It appears that most of the genera isolated from cave silver at SURF in this study, as well detected by $16 \mathrm{~S}$ rRNA gene sequencing (Thompson \& Bergmann, 2016) are likely to be chemoheterotrophic or mixotrophic. However, the source of organic molecules utilized by cells in cave silver is not obvious, because the cave silver biofilms in SURF are not exposed to fracture water, but instead condense water on their surface. It is possible that volatile organic molecules, produced by extensive microbial biofilms where fracture water emerges $100 \mathrm{~m}$ down the tunnel, may be utilized by the cave silver.

A survey of cave silver biofilms using Illumina $16 \mathrm{~S}$ rRNA gene sequencing by Thompson and Bergmann (2016) indicated that Acinobacteria (especially Pseudonocardiaceae), Chloroflexi, Acidobacteria, Proteobacteria (especially Alphaproteobacteria) and Planctomycetes were the most abundant bacterial groups, with a total of 552 OTUs identified at a $97 \%$ level of similarity. We were not able to isolate any members of the Acidobacteria, Chloroflexi, or Planctomycetes in this study. We were able to isolate members of genera Dongia, Reynella, Bradyrhizobium, Variibacter, Pseudolabrys, Bauldia, Mesorhizobium, Micrococcus, Sporichthya, Allokutnzeria and Pseudonocardia. However, we estimate that the groups we isolated represent only $4.7 \%$ of the total $16 \mathrm{~S}$ rRNA gene sequences obtained from Illumina sequencing. Despite the fact that the isolates were obtained represent only a small fraction of the diversity of bacteria present in SURF cave silver biofilms, a number of isolates appear to represent previously uncultured species and genera in the Rhodospirillaceae. We hope that these may be characterized more fully, to provide inferences about their role in the cave silver community in SURF.

It is striking that the genera of cultivable bacteria from cave silver biofilms in limestone caves in Slovenia by Velikonja et al., (2014) were largely different from those isolated from cave silver in SURF. Although 16S rRNA gene analysis of community DNA indicated that both the Slovenian (Pasic et al., 2010) and SURF (Thompson \& Bergmann, 2016) cave silver communities had an abundance of Actinobacteria of the family Pseudonocardiaceae, Velikonja et al. (2014) isolated primarily Streptomyces, Rhodococcus, and Micrococcus; and did not isolate the genera Pseudonocardia, Amycolatopsis, and Allokutneria abundant in SURF isolates. Micrococcus was found in both Slovenian and SURF cave silver, however, and 16S rRNA gene sequence (an approximately 1360 $\mathrm{BP}$ long region) suggests that 13 Slovenian isolates (accession number KC978879) may represent the same species as SURF isolates $27 \mathrm{R}$ and $35 \mathrm{R}$; this was the only cultured species shared between these sites. This may partly reflect the different media used for each study, but it may also reflect that there are substantial differences in cultivable microbes in cave silver from SURF and from limestone caves.

It is likely that some of the bacteria in SURF cave silver may be derived from bacteria living in terrestrial habitats. Half of the bacterial isolates from SURF cave silver have greater than 98\% 16S rRNA gene identity (over their entire length) to bacterial isolates from surface habitats (Fig. 1). Even some SURF isolates which have less than 97\% 16S rRNA gene identity with surface isolates still show greater than 97\% 16S rRNA gene identity with environmental 16S rRNA gene libraries from surface habitats. For example, SURF isolates HS025C, HS063C, HS130C, and HS153C had $97.8 \%$ identity with a $16 \mathrm{~S}$ rRNA gene (accession number LN567343) from a refuse pile made by leafcutter ants; isolates HS063R and HS068R had 99.7\% identity with a 16S rRNA gene (AF234728) from activated sludge; and isolate HS138C had 98.8\% identity with a 16S rRNA gene (JF776953) from the rhizosphere of eggplant.

In general, our experience attempting to use culturebased techniques to recover bacteria from cave silver in SURF is similar to other recent attempts to recover bacteria from cave rocks using low-nutrient media (Barton, 2015; Ortiz et al., 2015; and Vellikonja et al., 2014) in that certain abundant cave phyla, such as Acidobacteria, Chloroflexi, and Planctomycetes are not recovered, while various species of Proteobroteobacteria and Actinobacteria, which are not the predominant members of the community, predominate in cultured isolates. In all cases, the species isolated were highly dependent on the media used. Nonetheless, culture-based techniques may be still useful, not so much to isolate the main members of cave silver communities, but to isolate and characterize new species of microbes, because both cave rock surfaces and SURF cave silver communities contain previously unknown species and even genera.

\section{ACKNOWLEDGEMENTS}

We would like to thank Oxana Gorbatenko (BHSU, Westcore) for her help with DNA sequencing. Ethan Thomson (BHSU), Tom Reagan (SURF), and Madeline Valentin (Augustana College, SD) assisted in sample collection. M. Valentin also assisted with isolate characterization. This work was funded through a 
grant from NSF (REU Grant \# 1560474) and a South Dakota Board of Regents Research and Development Innovation grant.

\section{REFERENCES}

Barton H.A. \& Jurado V., 2007 - What's up down there? Microbial diversity in caves. Microbe, 2: 132-138.

Barton H.A., 2015 - Starving artists: bacterial oligotrophic heterotropy in caves. In: Summers Engel A. (Ed.), Microbial life of cave systems. De Gruyter, Berlin, p. 79-104.

Caddey S., Bachman R., Campbell T., Reid R. \& Otto R., 1991 - The homestake gold mine, an early proterozoic iron-formation-hosted gold deposit, Lawrence County, South Dakota. U.S. Geological Survey Bulletin, 1857-J. https://doi.org/10.3133/b1857J

Carr G., Derbyshire E.R., Caldera E., Currie C.R. \& Clardy J., 2012 - Antibiotic and antimalarial quinones from fungus-growing ant-associated Pseudonocardia $s p$. Journal of Natural Products, 75: 1806-1809. https://doi.org/10.1021/np300380t

Curry M.D., Boston P.J., Spilde M.N., Baichtal J.F. \& Campbell A.R., 2009 - Cottonballs, a unique subaqeous moonmilk, and abundant subaerial moonmilk in Cataract Cave, Tongass National Forest, Alaska. International Journal of Speleology, 38: 111-128.

https://doi.org/10.5038/1827-806X.38.2.3

De Lillo A., Ashley F.P., Palmer R.M., Munson M.A., Kyriaco L., Weightman A.J. \& Wade W.G., 2006 Novel Subgingival bacterial phenotypes detected using multiple universal polymerase chain reaction primer sets. Oral Microbiology and Immunology, 21: 61-68. https://doi.org/10.1111/j.1399-302X.2005.00255.x

Edgar R.C., 2004 - MUSCLE: multiple sequence alignment with high accuracy and high throughput. Nucleic Acids Research, 32 (5): 1792-1797. https://doi.org/10.1093/nar/gkh340

Engel A.S., Stern L.A. \& Bennett P.C., 2004 - Microbial contributions to cave formation: New insights into sulfuric acid speleogenesis. Geology, 32: 369-372. https://doi.org/10.1130/G20288.1

Fortuna A.M., Marsh T.L., Honeycutt C.W. \& Halteman W.A., 2011 - Use of primer selection and restriction enzymes to assess bacterial community diversity in an agricultural soil used for potato production via terminal restriction fragment length polymorphism. Applied Microbiology and Biotechnology, 91: 1193-1202. https://doi.org/10.1007/s00253-011-3363-7

Harris J.E., 1985 - GELRITE as an agar substitute for the cultivation of mesophilic Methanobacterium and Methanobrevibacter species. Applied and Environmental Microbiology, 50: 1107-1109.

https://aem.asm.org/content/50/4/1107

Huse S.M., Dethlefsen L. Huber J.A., Welch D.M., Relman D.A. \& Sogin M.L., 2008 - Exploring microbial diversity and taxonomy using SSU rRNA hypervariable tag sequencing. PLoS Genetics, 4 (11): e1000255. https://doi.org/10.1371/journal.pgen.1000255

Jukes T.H. \& Cantor C.R., 1969 - Evolution of protein molecules. In: Munro H.N. (Ed.), Mammalian protein metabolism. Academic Press, New York, p. 21-123.

Labeda D.P. \& Goodfellow M., 2012 - Order XIII. Pseudonocardiales ord. nov. In: Goodfellow M., Kämpfer P., Busse H.-J., Trujillo M.E., Suzuki K., Ludwig W. \& Whitman W.B. (Eds.), Bergey's manual of systematic bacteriology (2 ${ }^{\text {nd }}$ Ed.), vol. 5. Springer, New York, 1301 p.

Lavoie K.H., Winter A.S., Read K.J.H., Hughes E.M., Spilde M.N. \& Northrup D., 2017 - Comparison of bacterial communities from lava cave microbial mats to overlying surface soils from Lava Beds National Monument, USA. PLoS ONE, 12 (2): e0169339. https://doi.org/10.1371/journal.pone.0169339

Lesko K.T., 2011 - The Homestake Interim Laboratory and Homestake DUSEL. Nuclear Physics, B - Proceedings Supplement, 221: 155-159.

https://doi.org/10.1016/j.nuclphysbps.2011.03.112

MacFaddin J.F., 1980 - Biochemical tests for identification of medical bacteria (2n Ed.). Williams \& Wilkins, Philadelphia, $527 \mathrm{p}$.

Moyes R.B., Reynolds J. \& Breakwell D.P., 2009 Differential staining of bacteria: Gram stain. Current Protocols in Microbiology, 15 (1): A.3C.1-A.3C.8. https://doi.org/10.1002/9780471729259.mca03cs 15

Mudder T.I. \& Whitlock J.L., 1984 - Strain of Pseudomonas paucimobilis. United States Patent Office, patent US 4461834A.

Mulec J., Oarga-Mulec A., Tomazin R. \& Matos T., 2015 - Characterization and fluorescence of yellow biofilms in karst caves, southwest Slovenia. International Journal of Speleology, 44: 107-114.

https://doi.org/10.5038/1827-806X.44.2.1

Northup D.E., Barns S.M., Lu L.E., Spilde M.N., Schelble R.T., Dano K.E., Crossley L.J., Conolly C.A., Boston P.J., Natvig D.O. \& Dahm C.N., 2003 - Diverse microbial communities inhabiting ferromanganese deposits in Lechuguilla and Spider Caves. Environmental Microbiology, 5: 1071-1086.

https://doi.org/10.1046/j.1462-2920.2003.00500.x

Northrup D.E., Melim L.A., Spilde M.N., Hathaway J.J.M., Garcia M.G., Moya M., Stone D., Boston P.J., Dapkevicius M.L.N.E. \& Riquelme C., 2011 - Lava cave microbial communities within mats and secondary mineral deposits: implications for life detection on other planets. Astrobiology, 11: 601-618. https://doi.org/10.1089/ast.2010.0562

Pašic L., Kove B., Sket B. \& Herzog-Velikonja B., 2010 - Diversity of microbial communities colonizing the walls of a Karstic cave in Slovenia. FEMS Microbiology Ecology, 71: 50-60. https://doi.org/10.1111/j.1574-6941.2009.00789.x

Portillo M.C., Gonzalez J.M. \& Saiz-Jimenez C., 2008 - Metabolically active microbial communities of yellow and grey colonizations on the walls of Altamira Cave, Spain. Journal of Applied Microbiology, 104: 681-691. https://doi.org/10.1111/j.1365-2672.2007.03594.x

Ortiz M., Nielson J.W., Legatzki A. \& Maier R.A., 2015Bacterial and archaeal diversity of cave speleothem and rock surfaces: A carbonate cave case study from Kartcher Caverns. In: Summers Engel A. (Ed.), Microbial life of cave systems. De Gruyter, Berlin, p. 105-124.

Osburn M.R., La Rowe D.E., Momper L.M. \& Amand J.P., 2014 - Chemolithotrophy in the continental deep subsurface: Sanford Underground Research Facility (SURF) USA. Frontiers in Microbiology, 5: 1-14. https://doi.org/10.3389\%2Ffmicb.2014.00610

Rastogi G., Muppidi G.L., Gurram R.N., Adhikari A., Bischoff K.M., Hughes S.R., Apel W.A., Bang S.S., Dixon D. \& Sani R.K., 2009a - Isolation and characterization of cellulose-degrading bacteria from the deep subsurface of the Homestake gold mine, Lead, South Dakota, USA. Journal of Industrial Microbiology and Biotechnology, 36: 585-598.

https://doi.org/10.1007/s10295-009-0528-9

Rastogi G., Stetler L.D., Peyton B.M. \& Sani R.K., 2009b - Molecular analysis of prokaryotic diversity in the deep subsurface of the former Homestake gold mine, South Dakota, USA. Journal of Microbiology, 47: 371-384. https://doi.org/10.1007/s12275-008-0249-1 
Rastogi, G, Gurram R.N., Bhalla A., Gonzalez R., Bischoff K.M, Hughes S.R., Kumar S. \& Sani R.K., 2013 Presence of glucose, xylose, and glycerol fermenting bacteria in the deep biosphere of the former Homestake gold mine, South Dakota. Frontiers in Microbiology, 4: 18. https://doi.org/10.3389/fmicb.2013.00018

Reasoner D.J. \& Geldreich E.E., 1985 - A new medium for the enumeration and subculture of bacteria from potable water. Applied and Environmental Microbiology, 49 (1): 1-7. https://aem.asm.org/content/49/1/1

Rhoads D.D., Cox S.B., Rees E.J., Sun Y. \& Wolcott R.D., 2012 - Clinical identification of bacteria in human chronic wound infections: culturing vs. 16S ribosomal DNA sequencing. BMC Infectious Disease, 12: 321. https://doi.org/10.1186/1471-2334-12-321

Sauro F., Cappelletti M, Ghezzi D., Columbu A., Hong P.Y., Zowawi H.M., Carbone C., Piccini L., Vergara F., Zannoni D. \& De Waele J., 2018 - Microbial diversity and biosignitures of amorphous silica deposits in orthoquartzite caves. Scientific Reports, 8: 17569. https://doi.org/10.1038/s41598-018-35532-y

Schlaberg R., Simmon K.E. \& Fisher M.E., 2012 - A systematic approach for discovering novel, clinically relevant bacteria. Emerging Infectious Diseases, 18 (3): 422-430. https://doi.org/10.3201/eid1803.111481

Suel-Silva M., Naves Sales A., Magalhães-Guedes T.K., Dias R.D. \& Schwan R.F., 2013 - Brazilian Cerrado soil Actinobacteria ecology. BioMed Research International, 2013: 503805.

https://doi.org/10.1155/2013/503805

Tamura T., Ishida Y., Otoguro M. \& Suzuki K.I., 2010 - Amycolatopsis helveola sp. nov. and Amycolatopsis pigmentata $s p$. nov., isolated from soil. International Journal of Systematic and Evolutionary Microbiology, 60: 2629-2633. https://doi.org/10.1099/ijs.0.017871-0

Tebo B.M., Davis R.E., Anitori R.P., Connell L.B., Schiffman P. \& Staudigel H., 2015 - Microbial communities in dark oligotrophic volcanic ice cave ecosystems of Mt. Erebus, Antarctica. Frontiers in Microbiology, 6: 179. https://doi.org/10.3389/fmicb.2015.00179

Thompson E. \& Bergmann D., 2016 - Microbial community structure of "cave silver" biofilms from the Sanford Underground Research Facility in Lead, South Dakota, as determined by 16S rRNA gene sequencing. Proceedings of the South Dakota Academy of Science, 95: 152.

https://sdaos.org/wp-content/uploads/pdfs/2016/ 152\%20Bergmann.pdf

Tomasiewicz D.M., Hotchkiss D.K., Reinbold G.W. Read R.B. \& Hartman P.A., 1980 - The most suitable number of colonies on plates for counting. Journal of Food Protection, 43 (4): 282-286.

https://doi.org/10.4315/0362-028X-43.4.282

Tomita K., Hoshino Y.T. \& Miyaki T., 1993 Kibdelosporangium albatum $s p$. nov., producer of the antiviral antibiotics cycloviracins. International Journal of Systematic Bacteriology, 43: 297-301.

https://doi.org/10.1099/00207713-43-2-297

Van Der Linde K., Lim B.T., Rondeel J.M.M, Antonissen L.P.M.T. \& De Jong G.M.Th., 1999 - Improved bacteriological surveillance of haemodialysis fluids: A comparison between Tryptic soy agar and Reasoner's $2 \mathrm{~A}$ media. Nephrology Dialysis Transplantation, 14 (10): 2433-2437.

https://doi.org/10.1093/ndt/14.10.2433

VanInsberghe D., Maas K.R., Cardenas E., Strachan C.R., Hallam S.J. \& Mohr. W.W., 2015 - Non-symbiotic Bradyrhizobium ecotypes dominate North American Forest soils. The ISME Journal, 9: 2435-2441. https://doi.org/10.1038/ismej.2015.54

Velikonja B.H., Tkavc R. \& Pasic L., 2014 - Diversity of cultivable bacteria involved in the formation of macroscopic microbial colonies (cave silver) on the walls of a cave in Slovenia. International Journal of Speleology, 43 (1): 45-56. https://doi.org/10.5038/1827-806X.43.1.5

Versalovic J., Schneider M., De Bruijn F. \& Lupski J., 1994 - Genomic fingerprinting of bacteria using repetitive sequence-based polymerase chain reaction. Methods in Molecular and Cellular Biology, 5: 25-40. http://libcatalog.cimmyt.org/download/ reprints/96416.pdf

Waddell E.J., Elliott T.J., Sani R.K., Vahrenkamp J.M., Roggenthen W.M., Anderson C.M. \& Bang S.S., 2010 Phylogenetic evidence of noteworthy microflora from the subsurface of the former Homestake gold mine, Lead, South Dakota. Environmental Technology, 31 (8-9): 979-991. https://doi.org/10.1080/09593331003789511

Wang Q., Garrity G.M., Tiedje J.M. \& Cole J.R., 2007 Naïve Bayesian Classifier for Rapid Assignment of rRNA Sequences into the New Bacterial Taxonomy. Applied and Environmental Microbiology, 73 (16): 5261-5267.

Weisburg W.G., Barns S.M., Pelletier D.A. \& Lane D.J., 1991 - 16S ribosomal DNA amplification for phylogenetic study. Journal of Bacteriology, 173 (2): 697-703. https://doi.org/10.1128/jb.173.2.697-703.1991

Yuan M., Yu Y., Li H.R., Dong N. \& Zhang X.H., 2014 - Phylogenetic diversity and biological activity of Actinobacteria isolated from the Chukchi shelf marine sediments in the Arctic Ocean. Marine Drugs, 12 (3): 1281-1297. https://doi.org/10.3390/md12031281 